\title{
Analysis of Copper Effect on Microstructures and Mechanical Properties in Microalloyed Steels
}

\author{
A. M. ELWAZRI, ${ }^{1)}$ A. FATEHI, ${ }^{1)}$ J. CALVO, ${ }^{1)}$ D. BAI ${ }^{2)}$ and S. YUE ${ }^{11}$ \\ 1) McGill University, Department of Mining, Metals and Materials Engineering, 3610 University Street, Montréal, Quebec, \\ Canada, H3A 2B2. $\quad$ 2) Research \& Development, IPSCO. Inc, P.O. Box 1670, Regina, SK, Canada, S4P 3 C7.
}

(Received on August 30, 2007; accepted on November 12, 2007)

\begin{abstract}
The microstructure and mechanical properties under cool deformation conditions was investigated for three steels of approximately $0.03 \%$ carbon with different alloying additions of niobium and copper. Compression testing of the three steels was employed to study the influence of processing conditions (cool deformation) and chemical composition (niobium and copper) on the microstructure and mechanical properties. Overall, for the steel compositions examined, the addition of copper increased the strength. This can be explained by solid solution hardening effect of copper. The results show that there is very fine equiaxed ferrite that has formed, either by recrystallization or transformation induced by cool deformation.
\end{abstract}

KEY WORDS: copper; cool deformation; Nb precipitates; ferrite matrix; mechanical properties; FE-SEM; strain hardening rate; microalloyed steels.

\section{Introduction}

Over the past three decades microalloyed steels, which possess an excellent combination of strength, toughness and weldability, have been extensively studied and applied. The strength improvement usually comes from two mechanisms, grain refinement and precipitation. During hot rolling $\mathrm{Nb}(\mathrm{C}, \mathrm{N})$ particles precipitate and can retard grain growth after recrystallization, and prevent recrystallization, leading to austenite pancaking, both mechanisms leading to grain refinement. Any Nb, which precipitates out in the ferrite, provides precipitation strengthening. ${ }^{1-3)}$

Recycling of steel scrap has become a very important concern from the standpoint of efficient use of energy and resources, as well as environment preservation. Nowadays industrial steels are often produced from scrap steels containing residual contents of several alloying elements, e.g. copper. There are beneficial effects of copper in a wide range of commercial steels, due to the fact that copper induces: i) grain refinement by lowering the austenite to ferrite transformation temperature ${ }^{4,5)}$ and ii) precipitation hardening after rapid cooling and ageing. Few studies have been done on residual copper contents $(\sim 0.5 \mathrm{wt} \%)$ in evaluating their precipitation possibility and effects on mechanical properties. ${ }^{6-9)}$ The aim of this study is to investigate the effect of small amount of $\mathrm{Cu}$ contents $(0.4 \mathrm{wt} \%)$ and high $\mathrm{Nb}$ contents $(0.07-0.09 \mathrm{wt} \%)$ on microstructure and mechanical properties of microalloyed steels undergoing cool deformations conditions.

\section{Experimental Procedure}

\subsection{Material}

Three steels grades, with chemical compositions as listed in Table 1, were examined. One steel A commercial manufactured by IPSCO Inc., and the two steels (laboratory) were prepared and cast and rolled at CANMET Materials Technology Laboratory in Ottawa, Canada. Steel A contains residual elements retained from the recycled steel, with $\mathrm{Cu}$ having the highest level. In previous work, the work of Wei et al. ${ }^{7)}$ for steel A revealed precipitates mainly consisting of $\mathrm{Cu}$ in the ferrite matrix, while the data of Elwazri et al. ${ }^{6,8)}$ showed only precipitates of $\mathrm{Nb}(\mathrm{C}, \mathrm{N})$ in the ferrite matrix. In this work, steels $\mathrm{B}$ and $\mathrm{C}$ were designed to clarify the effect of $\mathrm{Nb}$ and $\mathrm{Cu}$.

To determine the temperature needed to dissolve the $\mathrm{Nb}(\mathrm{C}, \mathrm{N})$ prior to thermomechanical treatments, the following equation was used ${ }^{10)}$

$$
\log \left([\mathrm{Nb}]\left[\mathrm{C}+\frac{12 \mathrm{~N}}{14}\right]\right)=2.26-\frac{6770}{T} .
$$

where $[\mathrm{Nb}],[\mathrm{C}],[\mathrm{N}]$ are the concentrations of these elements in the steel, and $T$ is the absolute temperature. The solution temperatures were calculated to be 1180,1175

Table 1. Chemical compositions of steels (wt $\%$ ).

\begin{tabular}{l|c|c|c|c|c|c|c|c|c}
\hline & $\mathrm{C}$ & $\mathrm{Mn}$ & $\mathrm{Si}$ & $\mathrm{Cu}$ & $\mathrm{Nb}$ & $\mathrm{Ti}$ & $\mathrm{Mo}$ & $\mathrm{N}$ & Others \\
\hline $\mathrm{A}$ & 0.038 & 1.8 & 0.28 & 0.42 & 0.09 & 0.02 & & 0.0092 & $\mathrm{Ni}, \mathrm{Mo}$ \\
\hline $\mathrm{B}$ & 0.049 & 1.6 & 0.08 & 0.4 & 0.07 & 0.02 & 0.3 & 0.009 & \\
\hline $\mathrm{C}$ & 0.039 & 1.6 & 0.08 & & 0.07 & 0.02 & 0.3 & 0.009 & \\
\hline
\end{tabular}


and $1149^{\circ} \mathrm{C}$ for steel $\mathrm{A}$, steel $\mathrm{B}$ and steel $\mathrm{C}$, respectively. In order to ensure that all $\mathrm{Nb}(\mathrm{C}, \mathrm{N})$ precipitates are dissolved, a reheating temperature higher than the calculated equilibrium temperature was used, which was selected to be $1200^{\circ} \mathrm{C}$. The specimens were heated to $1200^{\circ} \mathrm{C}$ and held at this temperature for $20 \mathrm{~min}$ to ensure significant dissolution of the $\mathrm{Nb}$ precipitates present in the initial microstructure.

\subsection{Cool Deformation Schedules}

After reheating in a radiant furnace mounted on the columns of the MTS load frame, specimens were cooled at $1^{\circ} \mathrm{C} \cdot \mathrm{s}^{-1}$ to the test temperature $\left(400^{\circ} \mathrm{C}\right)$, and were held for $5 \mathrm{~min}$ to homogenize the temperature within the specimen. The specimens were then compressively deformed at strains between 0.06 and 0.2 at a constant strain rate $\left(1 \mathrm{~s}^{-1}\right)$ and held at this temperature from $10 \mathrm{~min}$ up to $180 \mathrm{~min}$. This was followed by air-cooling the specimens to room temperature.

\subsection{Aged Only Specimens}

Selected specimens were reheated as before, and then aged at $400^{\circ} \mathrm{C}$ for times ranging from 10 to $180 \mathrm{~min}$ followed by air-cooling. This assesses the effect of aging without deformation.

\subsection{Microstructural Analysis}

Specimens for optical microscopy and field emission scanning electron microscopy (FE-SEM) microstructural analysis were prepared using standard metallographic procedures. These specimens were etched with $3 \%$ nital to reveal the overall microstructure. In order to characterize the ultra-fine precipitates, high resolution imaging techniques are required. Normally, this would involve characterization using a transmission electron microscope (TEM). FE-SEM conventionally involves the analysis of bulk specimens. ${ }^{11)}$ In this work, the FE-SEM can be alleviated by using thin specimens which would normally be used in the TEM, such as carbon extraction replicas or thin foils, since interaction volume effect is greatly reduced. ${ }^{12-14)}$ Since an accelerating voltage of $30 \mathrm{kV}$ gave the best results for the EDS analysis, this voltage was used to analyze smaller particles. Thin foils, the specimens were electro-polished by a Struers Tenupol-3 twin jet polisher was used for final thinning with a solution containing $6 \%$ perchloric acid in methanol cooled to $-30^{\circ} \mathrm{C}$ and with a voltage of $30 \mathrm{~V}$. The thin foils were then etched in $2 \%$ nital for $2 \mathrm{~s}$ to better reveal the microstructure for FE-SEM analysis.

\subsection{Shear Punch Testing}

The room temperature mechanical properties were determined by the shear punch test method, as noted above. Slices from the specimens were cut and ground (600 grit $\mathrm{SiC}$ finish) to approximately $300-350 \mu \mathrm{m}$ in thickness and placed between a die and washer assembly fitted on a lower housing. It has been previously shown that such a thickness variation has a negligible effect on the shear punch measured material properties. ${ }^{15)}$ A flat tip cylindrical punch (1.5 $\mathrm{mm}$ in diameter) fitted in an upper housing was forced through the specimen, the action of which punched out a circular disc. Since the upper and lower housings were attached to a servohydraulic materials testing system, load-

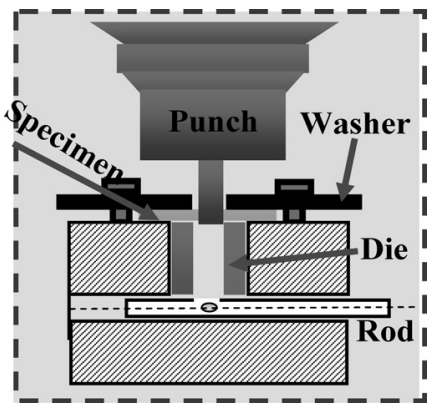

Fig. 1. Schematic of the shear punch apparatus.

displacement data could be obtained from the shear punch test, as shown in Fig. 1. As correlations between the shear punch data and tensile test data have been identified previously, the tensile flow properties, including YS, UTS and EL, can be determined using the following empirical equations $^{15,16)}$ :

$$
\begin{gathered}
\sigma=\frac{\sigma_{\text {eff }}}{C_{\sigma}}=\frac{L}{C_{\sigma} \cdot 2 \pi r t} \\
\varepsilon=\frac{\varepsilon_{\text {eff }}}{C_{\varepsilon}}=\frac{D}{C_{\varepsilon} \cdot t} \ldots
\end{gathered}
$$

where $\sigma$ is the tensile uniaxial stress $(\mathrm{MPa}), \sigma_{\text {eff }}$ is the effective stress in shear (MPa), $L$ is the load $(\mathrm{N}), r$ is the punch radius $(\mathrm{mm}), t$ is the specimen thickness $(\mathrm{mm}), \varepsilon$ is the tensile uniaxial strain, $\varepsilon_{\text {eff }}$ is the effective strain in shear, $D$ is the displacement (mm) and $C_{\sigma}, C_{\varepsilon}$ are empirical correlation coefficients for the YS/UTS and EL, respectively. The correlation coefficients are obtained by performing linear regressions (through zero) for the following ratios ${ }^{16,17)}$ :

$$
\begin{gathered}
\frac{\sigma_{\text {eff }}}{\sigma}=\frac{\frac{L}{2 \pi r t}}{\frac{F}{A_{0}}}=C_{\sigma} \\
\frac{\varepsilon_{\text {eff }}}{\varepsilon}=\frac{\frac{D}{t}}{\frac{l_{\mathrm{f}}-l_{0}}{l_{0}}}=C_{\varepsilon}
\end{gathered}
$$

where $F$ is the force in tension, $A_{0}$ is the initial cross-sectional area of the gauge length of a tensile specimen, $l_{\mathrm{f}}$ is the final length and $l_{0}$ is the initial length of the tensile specimen. The correlation coefficients are based on measurements of shear punch and tensile testing of a wide range of materials.

\section{Results and Discussions}

\subsection{Microstructure}

\subsubsection{Optical Microcopy}

Optical micrographs of the three steels (steel A, steel B and steel $\mathrm{C}$ ) in the as cool deformed and aged only conditions are shown in Fig. 2. The microstructures of the steels $\mathrm{A}, \mathrm{B}$ and $\mathrm{C}$ mainly consist of granular bainite. This struc- 

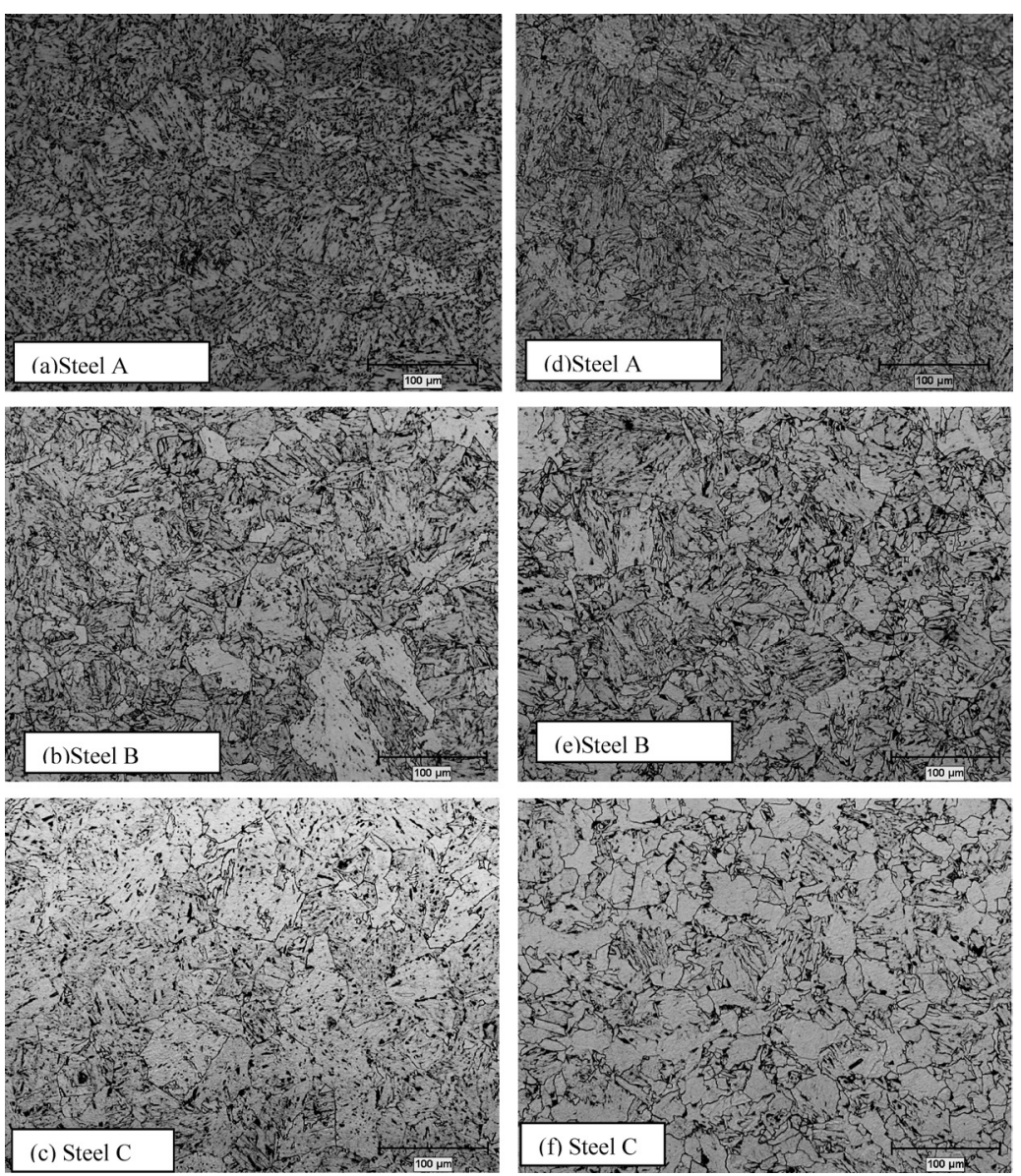

Fig. 2. Optical micrographs showing the microstructures after aging $30 \mathrm{~min}$ for steel $\mathrm{A}$, steel $\mathrm{B}$ and steel $\mathrm{C}$ steels (a, b, c) Aged only (d, e, f) Cool deformation at strain 0.2.

ture includes irregular ferrite with islands of second phases distributed between ferrite grains. The second phases can be pearlite and/or acicular ferrite. It can be seen clearly that grains are refined after cool deformation for all steels as compared with the aged only condition. This can be explained either by recrystallization or strain induced transformation. ${ }^{6}$ As well, after cool deformation steel $\mathrm{C}$ seems to have formed a significant volume fraction of polygonal ferrite, which again may be due to strain induced transformation.

In the case aged only, Figs. 2(a)-2(c) show an average grain size of about $22,25,30 \mu \mathrm{m}$ for steel A, B and C, respectively. However, cool deformation was observed to produce a mixture of fine and coarse grains with the microstructure having an average grain size of about 15, 18, $25 \mu \mathrm{m}$ (Figs. 2(d)-2(f)).

\subsubsection{Cool Deformation Flow Curves}

Figure 3 compares the true stress versus true strain curves obtained in the compression tests for the steels A, B and $\mathrm{C}$ at $400^{\circ} \mathrm{C}$ and a strain rate of $1 \mathrm{~s}^{-1}$. It can be seen that there is a significant difference between the flow stress levels that reflect the compositional differences in these microalloyed steels. In particular, steel A has highest level of the $\mathrm{Nb} 0.09 \%$, exhibiting the highest flow stress. The higher $\mathrm{Nb}$ content (steel $\mathrm{A}$ ) is associated with an increment of flow stress to a maximum of about $100 \mathrm{MPa}$ as compared with the steels $\mathrm{B}$ and $\mathrm{C}$. This may be due to a number of $\mathrm{Nb}$

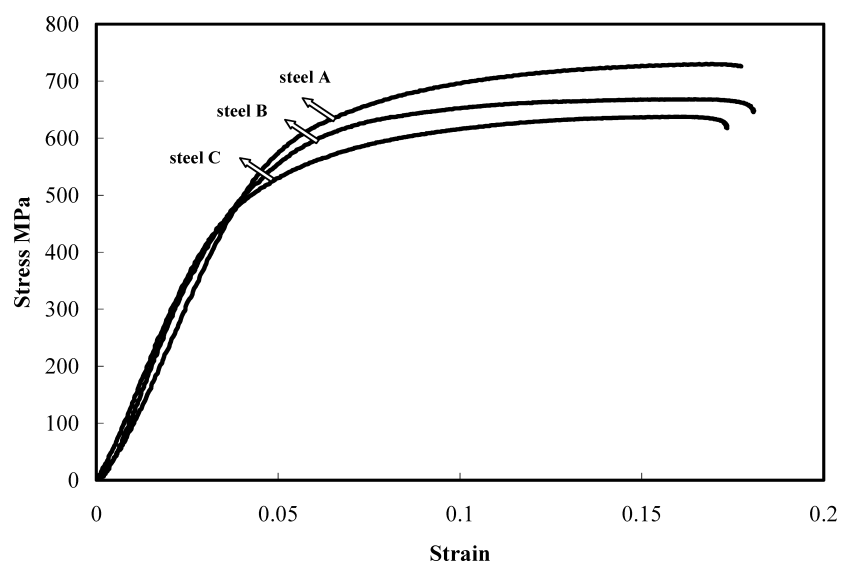

Fig. 3. The true stress versus true strain curves for steel $\mathrm{A}$, steel $\mathrm{B}$ and steel $\mathrm{C}$ at $400^{\circ} \mathrm{C}$ and strain rate of $1 \mathrm{~s}^{-1}$.

related factors, i.e. solid solution strengthening, differences in phases present, precipitate characteristics. Steel A also seems to maintain a level of work hardening throughout the deformation, whereas the other steels show steady state at strains above about 0.1 . It can be seen that there is a significant difference between the flow strength of the $\mathrm{B}$ and $\mathrm{C}$ steels, with the higher $\mathrm{Cu}$ addition in steel $\mathrm{B}$ exhibiting a higher flow stress. This is probably related to the solid solution effect associated with $\mathrm{Cu}$. 


\subsection{Room Temperature Mechanical Properties}

\subsubsection{Analysis of Shear Punch Curves}

Typical load-displacement curves illustrating the effect of thermomechanical processing and chemical composition are represented in Fig. 4. By using the same specimen thickness for all tests, the shear force-displacement behavior of the three steels and various conditions can be compared. Generally, the effect of $0.06 \mathrm{cool}$ deformation strain is marked with regard to flow strength. As well, cool deformation appears to increase the initial rate of work hardening compared to the aged only specimen. Increasing the strain to 0.2 generates the same flow behavior as for the 0.06 cool deformation, but with a higher flow stress. The effect of chemical composition is similar to that which was revealed in the cool deformation flow curves of Fig. 3, i.e. steel A has the highest flow stress, and steels $\mathrm{B}$ and $\mathrm{C}$ show similar curves.

The shape of the flow curves may give some information about any microstructural changes that may have taken place. The curve shape is largely controlled by the work hardening rate. Hence the rate of work hardening is plotted with displacement in Figs. 3 and 4 for the curves shown in Fig. 4. Using the method of Elwazri et al. ${ }^{18,19)}$ and Stewart et $a l .,{ }^{20)}$ the load-displacement data were fitted to a 9th order polynomial regression, which was then differentiated with respect to displacement to determine the strain-hardening rate.

The strain-hardening rate values were then plotted as a function of the displacement at cool deformation 0.2 for
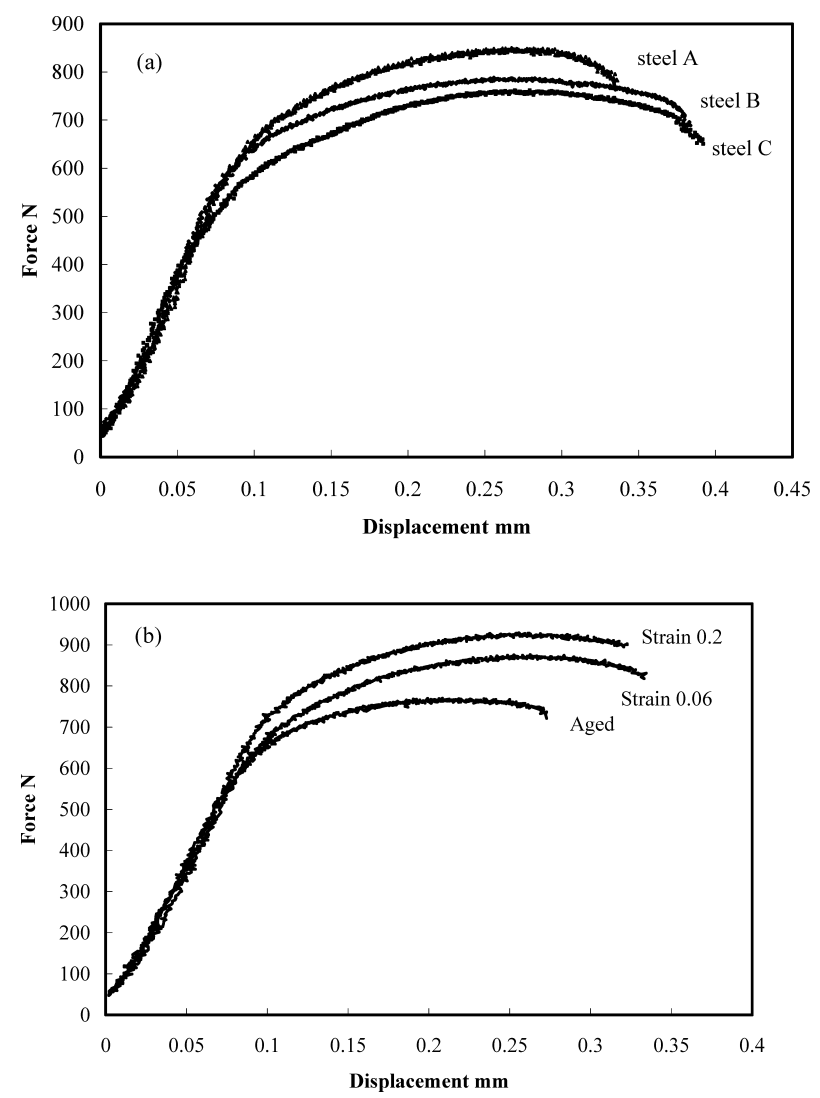

Fig. 4. Force versus displacement curves of the shear punch test for (a) steel A, steel B and steel C (aged for $30 \mathrm{~min}$ ) at cool deformation 0.06 , (b) steel A (aged for $30 \mathrm{~min}$ ) at different of cool deformation conditions. steel A, as shown in Fig. 5. In general, in a material where flow is basically dislocation motion, the work hardening rate will decrease with strain as it reaches a 'saturation' density of dislocation. Here, three plastic deformation regions can be identified, essentially delineated by the elastic limit (this part of the work hardening rate curve is out of range) and a near plateau segment defined as region II which is bookended by regions I and III. At present, the mechanisms leading to these three regions (in particular, region II) have not been elucidated. However, these features can be used as another way to categorise the any differences of the flow curves.

In the case of the effect of cool deformation for steel A, as shown in Fig. 6(a), region I is similar for the aged only

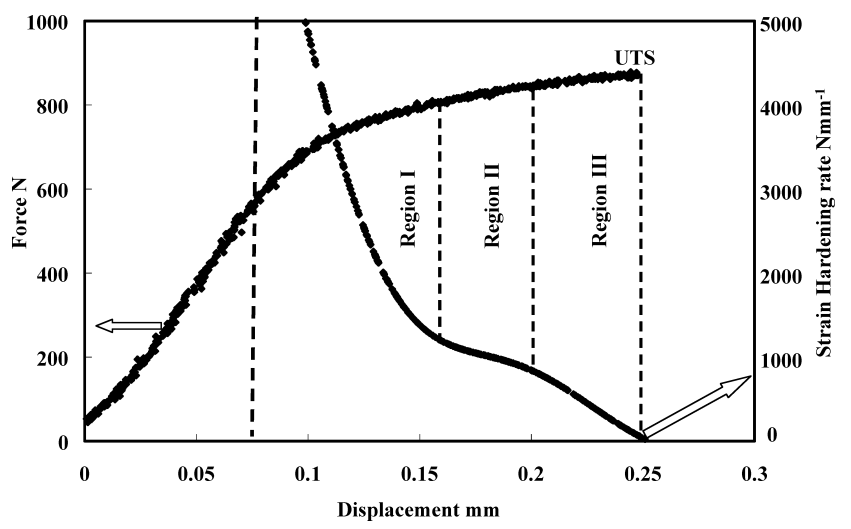

Fig. 5. Strain hardening rate and force versus displacement for steel $\mathrm{A}$ at cool deformation 0.2 .
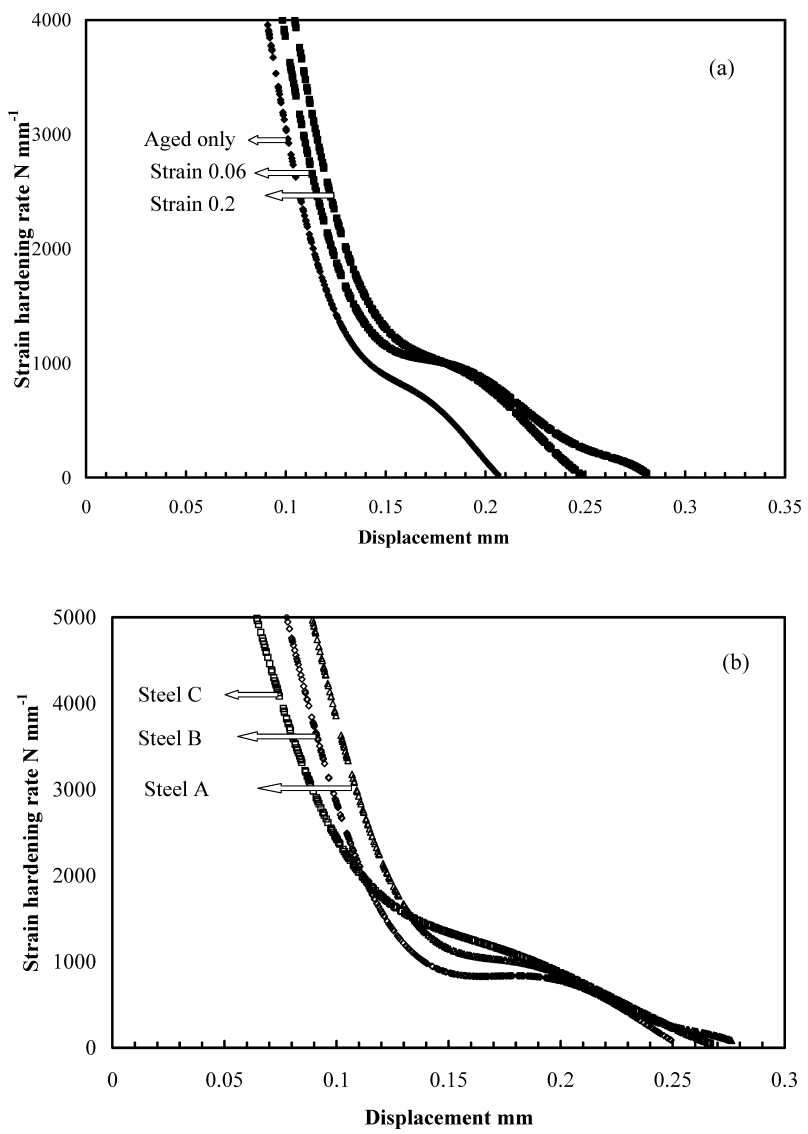

Fig. 6. Strain hardening rate versus displacement (a) for steel A at different cool deformations conditions (b) at strain 0.06 for steel A, steel B and steel C. 
curve and the steels subjected to cool deformation, but at $0.15 \mathrm{~mm}$ (region II) has a lower work hardening rate as compared with cool deformations. In region II the two cool deformations curves show almost identical behavior, with a flatter plateau and a higher work hardening rate in this region compared to the aged only curve.

The effect of chemical compositions for the steels that have been subjected to 0.06 cool deformations is shown in Fig. 6(b). Basically, steels A and B have similar behaviors but steel $\mathrm{C}$ differs from these two in regions I and mainly in region II. In region II, the plateau region is not as flat as the other steels, but the level of work hardening is similar. This suggests that steels A and B belong to the same 'family'; the common alloying characteristic might be the combination of $\mathrm{Cu}$ and $\mathrm{Nb}$, which is not present in steel $\mathrm{C}$, which has $\mathrm{Nb}$, but no $\mathrm{Cu}$.

\subsubsection{Effect of Cool Deformation on Strength}

Cool deformation generally increased the strength of three steels, but the extent of the effect is quite different for

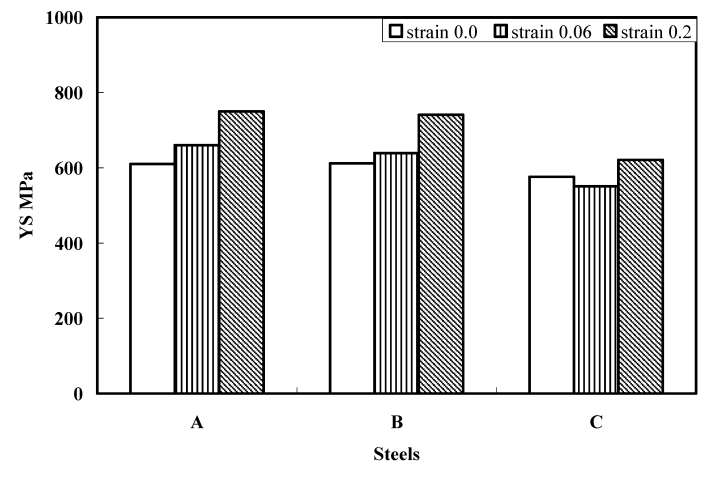

a) $10 \mathrm{~min}$

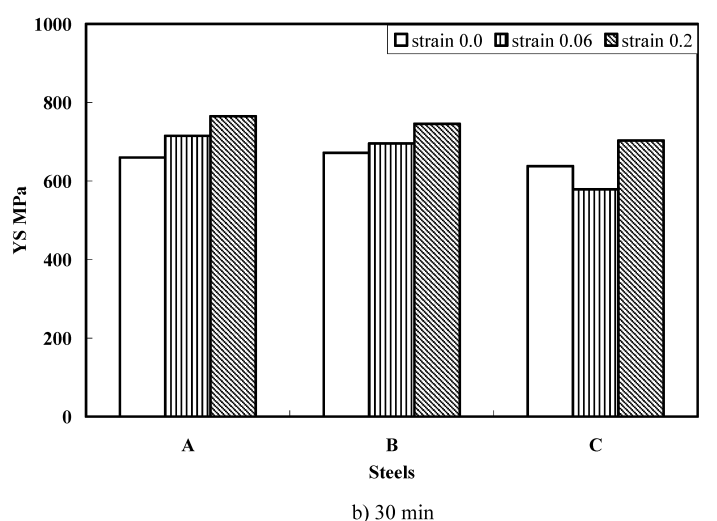

$30 \mathrm{~min}$

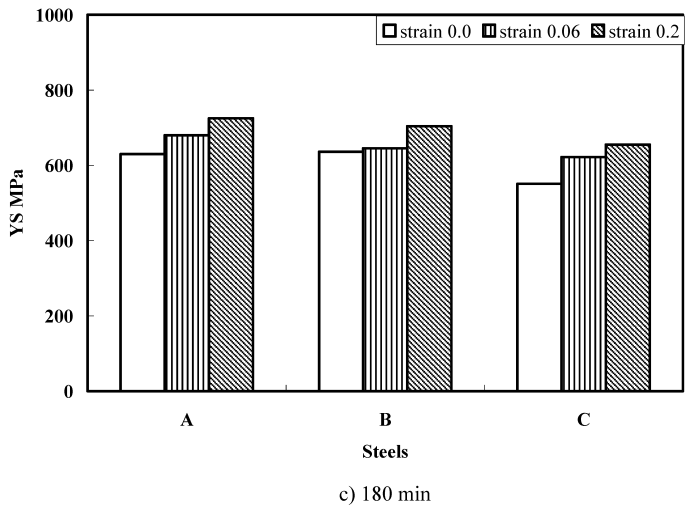

each steel, as shown in Fig. 7. The effect of strain 0.06 is somewhat variable, increasing both the yield and tensile strengths of steels A and B significantly after all ageing times, compared to the aged only condition, but decreasing the strength of steel $\mathrm{C}$ after 10 and $30 \mathrm{~min}$ cool deformation ageing. This level of strain is difficult to precisely achieve. Since it is very close to the elastic limit, it may be that some of these tests do not reach plastic yielding, which may explain why some results do not show an increase in room temperature strength.

However, for all three steels, increasing the cool deformation to 0.2 leads to the highest strength. The effect on yield strength is similar for all steels, although steel C tends to exhibit slightly lower values. With regard to ultimate tensile strength, steel A is clearly superior, and also exhibits the highest increment of ultimate tensile strength increase. In terms of effect of ageing time, $30 \mathrm{~min}$ seems to maximize both yield strength and ultimate tensile strength. As mentioned earlier, ${ }^{6,21)}$ this increase can be attributed to i) strain induced precipitation of precipitate forming alloying
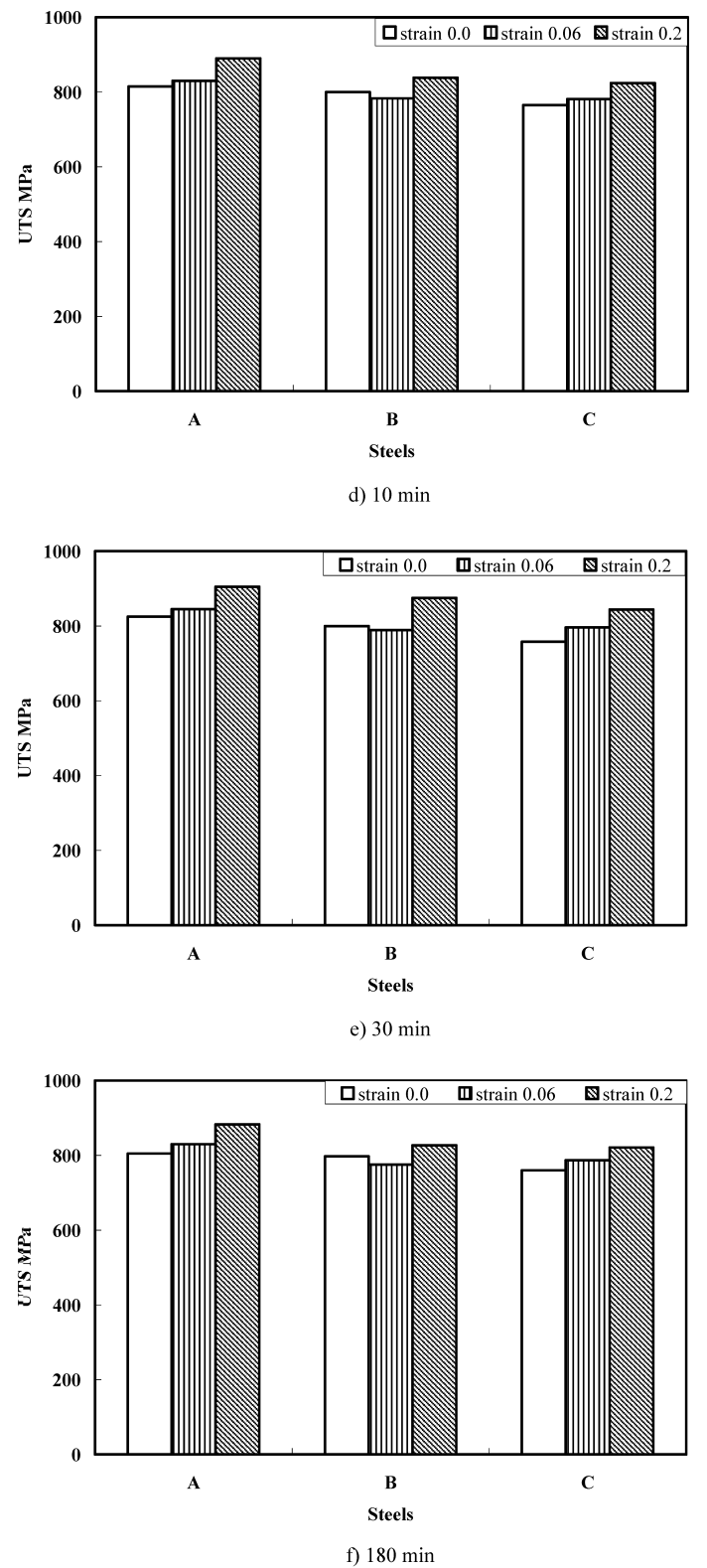

Fig. 7. Strength variations of three steels by cool deformation and aging time: (a, b, c) yield strength and (d, e, f) ultimate tensile strength. 


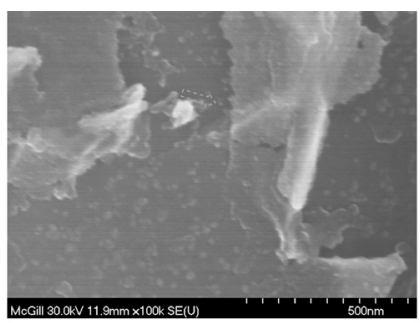

a)

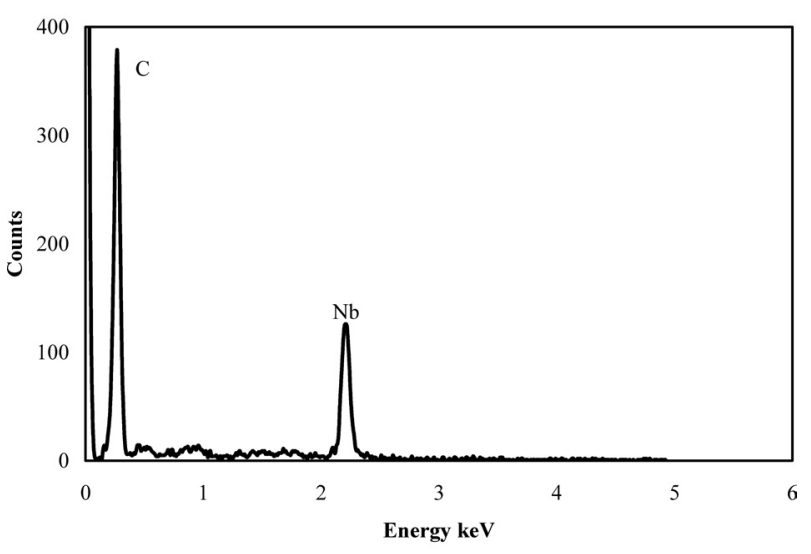

b)

Fig. 8. FE-SEM analysis of $5 \mathrm{~nm}$ size precipitates: (a) SE image of particle and (b) EDS spectrum showing Nb peak.

element $(\mathrm{Nb}, \mathrm{Ti})$, in ferrite matrix ii) work hardening due to dislocation accumulation in the matrix and around the grain boundaries preventing slip of other dislocations.

\subsubsection{Effect of Chemical Composition}

As noted above, steel A, appears to be most strongly affected by cool deformation. Steel $\mathrm{A}$ has higher $\mathrm{Nb}$ level $(0.09 \mathrm{Nb})$ than either steel B or C $(0.07 \mathrm{Nb})$. This could explain the superiority of steel A. However, there is clearly a strengthening effect of $\mathrm{Cu}$, when comparing steels $\mathrm{B}$ and $\mathrm{C}$. This strength increase may be related two effects: i) precipitation of $\mathrm{Nb}(\mathrm{C}, \mathrm{N})$ in ferrite ii) solid solution hardening effect of copper or clustering effect of copper in ferrite grains.

As mentioned above, there are conflicting reports regarding observations of copper-related precipitates in steel A. To examine the precipitates in steel A after 0.2 strain cool deformation, aged for $30 \mathrm{~min}$, a thin foil were made and examined in FE-SEM as presented in Fig. 8. Figure 9 shows a distribution of precipitate sizes. It can be seen that the very small precipitates ranging from about 3 to $10 \mathrm{~nm}$ were observed. The average precipitate size is about $4 \mathrm{~nm}$. Most of these precipitates were identified as $\mathrm{NbC}$ by EDX analysis, the peak corresponding to niobium can be found, as shown in Fig. 9(b). Note that the spectrum does not indicate the presence of copper. Bai et al. ${ }^{9}{ }^{9}$ have detected ultra-fine $\mathrm{NbC}$ precipitates with sizes below $5 \mathrm{~nm}$ in a $0.054 \mathrm{C}$, $0.09 \mathrm{Nb}, 0.4 \mathrm{Cu}$ steel are present in the $1 \%$ pre-strain at $450^{\circ} \mathrm{C}$ aged sample ( $5 \mathrm{~min}, 15 \mathrm{~min}, 45 \mathrm{~min}$ and $2 \mathrm{~h}$ ) and do not indicate any $\mathrm{Cu}$ precipitates (below $5 \mathrm{~nm}$ ) using transmission electron microscopes. Takahash and Iino ${ }^{22)}$ studied the effect of copper addition (1 to $3 \%$ ) on linepipe steels with $0.04 \mathrm{C}$ and $\mathrm{Nb} 0.04 \%$. The hot rolling and fast cooling $55^{\circ} \mathrm{C} \cdot \mathrm{s}^{-1}$ at $550^{\circ} \mathrm{C}$ aged for $30 \mathrm{~min}$ of the $1.7 \% \mathrm{Cu}$ con-

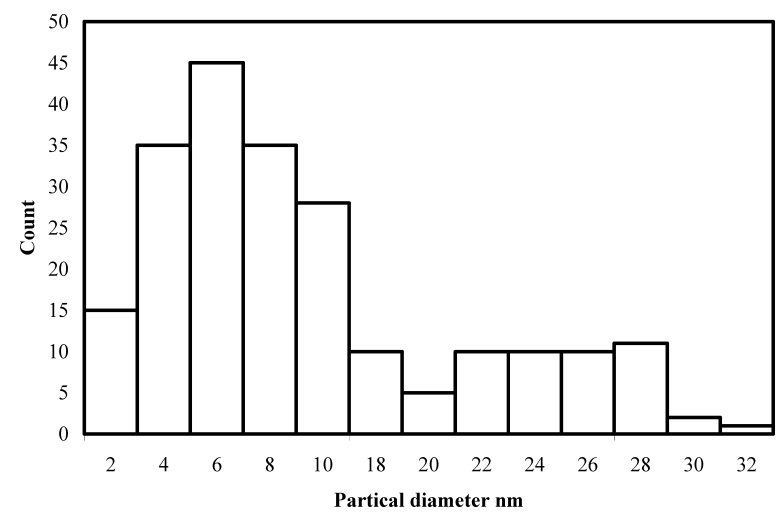

Fig. 9. Distribution of precipitate size.

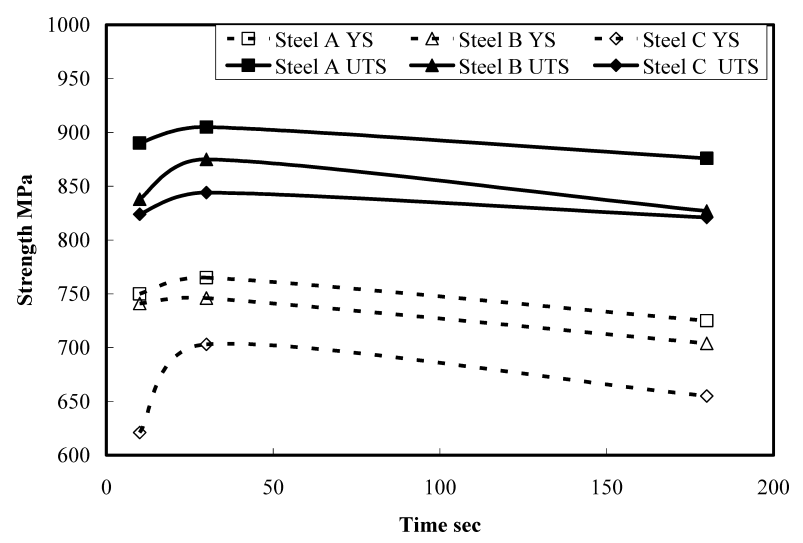

Fig. 10. Dependence of strength on aging time, showing yield strength ((broken line) and ultimate tensile strength (solid line) for all steels.

taining steel, no marked precipitation is observed using transmission electron microscopes. However, according Deschamps et al. $^{23)}$ found that, in a $0.8 \mathrm{wt} \% \mathrm{Cu}, 10 \%$ predeformed at room temperature and aged for $100 \mathrm{~h}$, very fine $(2-20 \mathrm{~nm}) \mathrm{Cu}$ precipitates were observed.

\subsubsection{Effect of Aging Time}

All specimens exhibited an initial strength peak, followed by a drop, as shown in Fig. 10. The times at which these phenomena occur vary with both composition and thermomechanical processing conditions. There is always an optimum precipitate size and number in order to get the best age hardening after a certain aging time. Further increasing this time leads to overaging conditions resulting from excessive growth of precipitates which affects the strength. This further indicates that precipitation strengthening is a key strengthening mechanism.

\section{Conclusions}

(1) Cool deformation increases the yield strength and ultimate tensile strength of all steels when compared to aged only specimens.

(2) The yield and tensile strength of the steel B and the steel A could be enhanced as the amount of $\mathrm{Cu}$ content in the steels was increased as compared with the steel $\mathrm{C}$. This can be explained by solid solution hardening effect of copper.

(3) Grains are refined after cool deformation for all 
steels as compare with the aged only condition. This can be explained either by recrystallization or transformation induced by cool deformation.

(4) The strength is higher for all the steels after $30 \mathrm{~min}$ aging when compared to 10 and $180 \mathrm{~min}$ aging times. It can be related to the optimum precipitates size after this aging time.

(5) Three plastic deformation regions were determined from flow force-displacement and strain hardening rate curves.

(6) The variations of instantaneous work hardening rate as a function of displacement have been successfully used to interpret the tensile work hardening behavior of processing and chemical composition.

(7) It can be seen that the very small precipitates ranging from about 3 to $10 \mathrm{~nm}$ were observed. Most of these precipitates were identified as $\mathrm{NbC}$. There is no precipitation of copper for these steels.

\section{Acknowledgement}

The authors would like to thank Natural Sciences and Engineering Research Council of Canada (NSERC) for their financial support. The authors would also like to acknowledge Edwin Fernandez for his technical assistance.

\section{REFERENCES}

1) C. M. Sellars: Mater. Sci. Technol., 6 (1990), 1072.

2) L. J. Cuddy: Metall. Trans. A, 15A (1984), 87.

3) W. J. Liu and J. J. Jonas: Metall. Trans. A, 19A (1988), 1403

4) J. Calvo, A. M. Elwazri and S. Yue: MS\&T 07 Conf. Proc., AIST, Warrendale, PA, USA, (2007), 233.
5) P. J. Othen, H. L. Jenkins and G. D. W. Smith: Philos. Mag. Lett., 64 (1991), 383.

6) A. M. Elwazri, D. Bai, F. Siciliano and S. Yue: Can. Metall. Q., 45 (2006), 441.

7) Q. Wei, J. Qu, A. M. Elwazri, D. Bai and S. Yue: MS\&T 04 Conf. Proc., AIST, Warrendale, PA, USA, (2004), 531.

8) A. M. Elwazri, R. Varano, F. Siciliano, D. Bai and S. Yue: Metall. Mater. Trans. A, 36A (2005), 2929.

9) D. Q. Bai, F. Hamad, J. Asante and S. Hansen: Mater. Sci. Forum, 500-501 (2005), 481.

10) K. J. Irvine, F. B. Pickering and T. Gladman: J. Iron Steel Inst., 205 (1967), 161.

11) A. M. Elwazri, R. Gauvin, P. Wanjara and S. Yue: J. Steel GRIPS, 3 (2004), 284.

12) R. Gauvin, K. Robertson, P. Horny, A. M. Elwazri and S. Yue: JOM, 58 (2006), 20.

13) A. M. Elwazri, R. Varano, F. Siciliano, D. Bai and S. Yue: Mater. Sci. Technol., 22 (2006), 537.

14) R. Varano, A. M. Elwazri, F. Siciliano, D. Bai and S. Yue: Mater. Sci. Forum, 500-501 (2005), 663.

15) A. M. Elwazri, R. Varano, P. Wanjara and S. Yue: Can. Metall. Q., 45 (2006), 33.

16) A. M. Elwazri: Ph. D. Thesis, McGill University, Montreal, (2004).

17) G. R. Stewart, A. M. Elwazri, R. Varano, S. Yue and J. J. Jonas: Mater. Sci. Eng. A, A420 (2006), 115.

18) A. M. Elwazri, P. Wanjara and S. Yue: Mater. Sci. Technol., 20 (2004), 1469.

19) C. M. Bae, A. M. Elwazri, D. L. Lee and S. Yue: ISIJ Int., 47 (2007), 1633.

20) G. R. Stewart, A. M. Elwazri, S. Yue and J. J. Jonas: Mater. Sci. Tech., 22 (2006), 519.

21) A. Fatehi, J. Calvo, A. M. Elwazri, D. Q. Bai and S. Yue: MS\&T 07 Conf. Proc., AIST, Warrendale, PA, USA, (2007), 243.

22) A. Takahash and M. Iino: ISIJ Int., 36 (1996), 241.

23) A. Deschamps, M. Militzer and W. J. Poole: ISIJ Int., 41 (2001), 41. 